\title{
Regional features of agriculture development of the Republic of Sakha (Yakutia)
}

\author{
Ekaterina Fedorova ${ }^{1, *}$, and Paraskovya Fedorova $^{2}$ \\ ${ }^{1}$ Federal Research Centre "The Yakut Scientific Centre of the Siberian Branch of the Russian Academy \\ of Sciences", Yakusk, Russian Federation \\ ${ }^{2}$ Arctic State Agrotechnological University, Yakusk, Russian Federation
}

\begin{abstract}
The article reveals development peculiarities of agriculture in the Republic of Sakha (Yakutia). The most important factor determining the social and economic development of Yakutia including agricultural sectors is its location in the Far North. In this regard, the main problems of regional agro-food complex development are studied, being the conduct of agricultural production in harsh natural and climatic conditions, seasonal nature of production, weak logistics and transport infrastructure, the complexity of agricultural producers to markets. The volume of gross regional product production per capita was analyzed. The main indicators of republican agriculture, as well as indicators of self-sufficiency level of basic agricultural products in Yakutia were considered. As a result of the study, the main specific features of agriculture development of the studied region were revealed.
\end{abstract}

\section{Introduction}

The Republic of Sakha (Yakutia) is the largest subject of the Russian Federation, occupying a fifth of its territory. Industry is represented mainly by mining industries and is the foundation of the economy of the republic. However, agriculture has a systemic and vital role [1]. Own agricultural production is aimed at providing the population with meat, milk, eggs, potatoes, vegetables. Production and consumption of fresh food is the main condition for the normal life of every person, especially given the impact of harsh natural and climatic conditions of the North. Thus, studies of the state and development of agriculture of Yakutia are necessary and preemptive. Distinctive features of agriculture in the region are: agricultural production in unfavorable territories, permafrost and short growing season conditions; high differentiation level of agroclimatic zones, preservation of traditional agricultural industries, hard-to-access agricultural land, seasonal nature of agricultural and commercial production associated with the inaccessibility of most rural areas; technological wear intensity of fixed assets in the production of agricultural products in unfavorable territories [2]. But the features listed above are also characteristic, for example, for YANAO, Kamchatka Krai, Northern Canada, Alaska, Denmark, Finland, Sweden and Norway. In this

\footnotetext{
*fedorova_ey@rambler.ru
} 
regard, we consider it necessary to identify the specifics of agriculture of the Republic of Sakha (Yakutia).

\section{Materials and methods}

Data from the Federal Service of State Statistics and State Statistics for the Republic of Sakha (Yakutia) [3] and other sources were used as materials for this study. Methodological tools for studying general issues of the republican culture economy was considered in the works of the following scientists: E.G. Egorov, V.R. Darbasov, N.N. Tikhonov et al. [4-6]. In the course of the study, general scientific research methods were used, including monographic, economic-statistical.

\section{Results and discussion}

The Republic is one of the most isolated and inaccessible regions of the world in terms of transport: more than $80 \%$ of the territory does not have year-round transport communication [7]. In particular, 175 rural settlements do not have year-round road connections to district centers. Note that in the republic there are 582 rural villages in 361 rural settlements, of which 156 settlements are inhabited by less than 500 people.

According to research, harsh climatic conditions are causing high costs, in particular on petroleum products (25-30\% higher), maintenance and repair of equipment (higher by 30 $35 \%$ ) [8]. The Republic conducts agricultural production in a vast area. For agricultural organizations, peasant holdings and citizens engaged in agricultural production in 2019, 64563 thousand hectares of land was fixed, which is $21 \%$ of the total area for Republic (308352 thousand ha). Agricultural land occupies 1640 thousand hectares, of which 105,3 thousand hectares are arable land.

$34 \%$ of the population of Yakutia lives in villages ( $25 \%$ in Russia). In general, over the past five years there has been a decrease in the rural population of the republic by 5,5 thousand people with simultaneous growth of the urban population by 11.4 thousand people. There are 194 hectares of agricultural territory and 5 hectares of agricultural land per villager. Such proportions require additional costs for the use of agricultural machinery and vehicles, reduces labor productivity. Labor productivity in the Republic of Sakha (Yakutia) in 2019 was $25 \%$ lower, and the cost of agricultural products was $35 \%$ higher than the average for the Russian Federation.

The problems of the economic situation of agriculture are solved by means of state support received from natural resources extracted in the territory of the republic. It should be noted that in general, the Republic of Sakha (Yakutia) is an effectively developing subject of the Russian Federation, which makes a worthy contribution to the economy of the country. In the Republic of Sakha (Yakutia) for 2016-2018, the gross regional product produced per capita was higher than the national average by $52.6 \%$ (Table 1 ).

Table 1. Gross regional product per capita

\begin{tabular}{|c|c|c|c|}
\hline Indicator & 2016 & 2017 & 2018 \\
\hline RS (Ya) & 897.5 & 951.2 & 1123 \\
\hline $\begin{array}{c}\text { On average in the } \\
\text { Russian Federation }\end{array}$ & 472.2 & 510.3 & 578.7 \\
\hline Relation & 52.6 & 53.6 & 51.5 \\
\hline
\end{tabular}


The share of agriculture in the gross regional product of the republic is insignificant and in 2019 amounted to $1.6 \%$, which is 26120.9 million rubles, including crop production 7822.9 million rubles, livestock products - 18298 million rubles. With the overall progress of the economy in the republic, agriculture in the gross regional product in the near future will still have a small share, yet it should have high quality indicators. However, the revival and further development of the industry is primarily a problem of full and sustainable funding [9].

Considering the dynamics of the main agriculture indicators of the Republic of Sakha (Yakutia) over the last five years, it is necessary to note the decrease in the number of cattle by $2.1 \%$, pigs - by $9.6 \%$, deer - by $2.5 \%$, poultry - by $8.4 \%$. The reduction in the number of pigs is due to the massive refusal of peasant holdings from large-scale breeding of pigs because of the advanced price growth for imported fodder. The number of horses increased by $3.6 \%$ (Table 2 ).

Table 2. Main indicators of agriculture of the republic

\begin{tabular}{|c|c|c|c|c|c|c|}
\hline Name & 2015 & 2016 & 2017 & 2018 & 2019 & $\begin{array}{l}2019 \text { to } \\
2015, \%\end{array}$ \\
\hline $\begin{array}{l}\text { Gross agricultural } \\
\text { production, million } \\
\text { rubles. }\end{array}$ & 20722.7 & 21930 & 24972.3 & 25781.1 & 26120.9 & 126.0 \\
\hline crop production & 6039.8 & 6512.4 & 7789.1 & 7974 & 7822.9 & 129.5 \\
\hline animal husbandry & 14682.9 & 15417.6 & 17183.1 & 17807.1 & 18298 & 124.6 \\
\hline \multicolumn{7}{|c|}{ Head count, heads } \\
\hline Livestock & 187207 & 186556 & 188049 & 183468 & 183299 & 97.9 \\
\hline Pigs & 23837 & 23149 & 23361 & 22447 & 21550 & 90.4 \\
\hline Horses & 176649 & 181505 & 184182 & 178184 & 183043 & 103.6 \\
\hline Deer & 156011 & 156835 & 154630 & 146585 & 152068 & 97.5 \\
\hline Poultry & 918432 & 983936 & 870897 & 852596 & 841315 & 91.6 \\
\hline \multicolumn{7}{|c|}{ Agricultural production of } \\
\hline $\begin{array}{l}\text { Livestock and poultry, } \\
\text { tons }\end{array}$ & 35504 & 35108 & 35802 & 35405 & 36881 & 103,9 \\
\hline Gross milk yield, tons & 164572 & 164644 & 166401 & 166055 & 161470 & 98.1 \\
\hline Eggs. thousand pcs & 136389 & 117961 & 121509 & 120648 & 133623 & 98.0 \\
\hline Cereals, tons & 8582 & 12781 & 6588 & 9586 & 10552 & 123.0 \\
\hline Potato, tons & 71925 & 78821 & 79253 & 82935 & 81482 & 113.3 \\
\hline Vegetables, tons & 35150 & 37303 & 38319 & 28284 & 26787 & 76.2 \\
\hline
\end{tabular}

Despite the reduction in the number of cattle and poultry, meat production (3.9\%) shows positive dynamics. Production growth was also achieved for grain crops $(23 \%)$ and potatoes (13\%). Geographical position of the Republic of Sakha (Yakutia), its separation from the territory of the country's intensive agricultural production, high costs for agricultural cargo transportation historically determined the main task of agro-industrial complex development - maximum provision of the republican population with food of local production. This task is solved to varying degrees. (Figure 1). Note that long transportation of food products reduces their quality and increases the cost. The volume of transport costs in the final price 
of food sales depends on the type of product, organization of delivery scheme, distance of transportation and shelf life of the product [10].

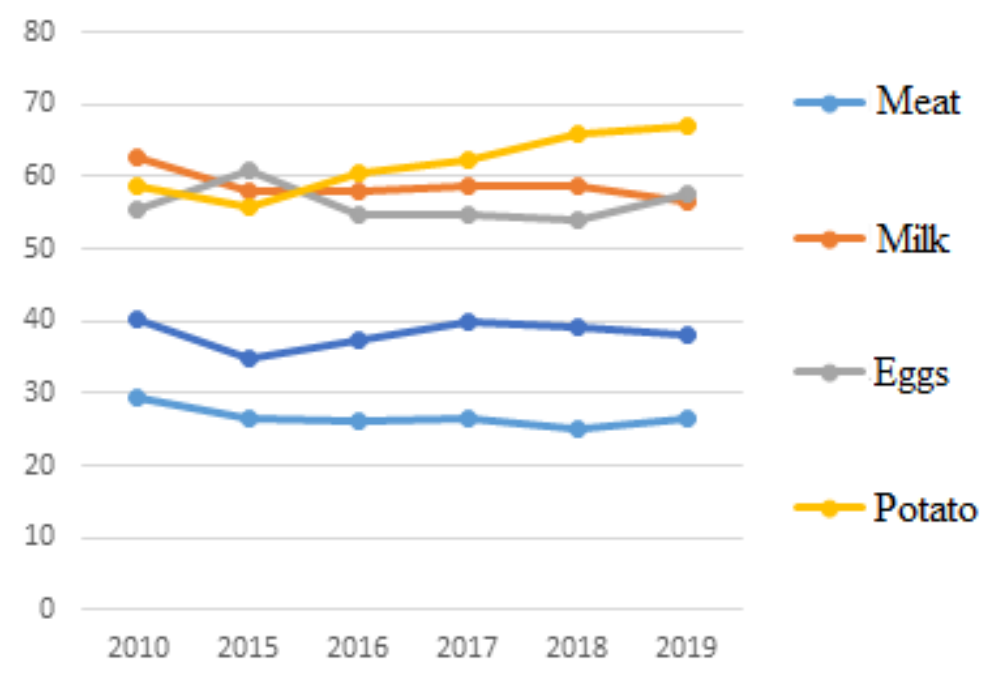

Fig. 1. Level of self-sufficiency of basic agricultural products in Yakutia

Figure 1 shows that the republic's provision of local food for the past 10 years remains almost unchanged. On average, between 40 and $70 \%$ of the region's food needs are met by importation from other regions of the country. Particularly difficult is the situation of the population in 13 arctic uluses of the republic, where the import of products is carried out mainly during the navigation period. It is obvious that all types of food cannot be produced in the studied region; food resources will be formed through a rational combination of local production and products delivery from other regions of the country and imports. At the same time, it is necessary to optimize the entire delivery system, in particular to choose reliable suppliers with quality products, a rational transportation scheme, etc.

Thus, to solve the problems of food supply of the republican population, we consider it necessary to settle the level of its main food provision of local production, as well as availability of financial resources and mechanisms for the delivery of food products in the appropriate amount and assortment.

According to information given by existing supply and distribution centers, there are difficulties in the participation of local producers in public procurement due to the formation of complex lots. Practically, this does not allow the manufacturer to directly participate in the bidding supplying only its products, because the lot includes an expanded list of goods. Under these conditions, producers are forced to speak on behalf of trading companies, selling their products at reduced value dictated by trading companies, or by bidding imported products that have documented compliance with technical conditions, but not always highquality.

\section{Conclusions}

The study makes it possible to conclude that agriculture is a traditional occupation of the population of the Republic of Sakha (Yakutia), having its own specific regional features:

1. These are primarily unfavorable conditions for the development of agriculture due to harsh climatic conditions, including agriculture in permafrost conditions and short 
vegetative period. Almost the entire territory of Yakutia is a zone of continuous centuriesold permafrost;

2. Traditional cattle breeding, horse herd farming, northern reindeer husbandry. Leading livestock industries represent aboriginal lifestyles. They preserve not only the way of life of the republican population, but also their well-being.

3. High cost of agricultural products due to high costs for its production, as well as difficulties with the sale of manufactured products due to low transport provision and undeveloped infrastructure of agricultural areas;

4. In Yakutia, local agricultural production should be considered not as purely entrepreneurial activity aimed at making profit, since the conditions for its receipt in this sector are initially objectively worse than in other sectors of the republic and in comparison with the profit from the import of products from other regions, but as the fulfillment of a socially significant economic function on the state order to provide the population of the republic with food, processing industry with raw materials, preservation of rural settlements as the basis of social control over the territories. It is not possible to refuse product importing, since full self-sufficiency is hard to achieve. In this aspect, it is necessary to preserve or even increase the subsidized import of grain, flour, fodder, including as a basis for the development of own livestock, bakery industry.

Here, only a general list of the republican agriculture development features is given, and a detailed information on its recommendations will be required during its further study.

Thus, sustainable development of agriculture and on its basis a decent population standard of living of the Republic of Sakha (Yakutia) requires development, justification and implementation of strategies and policies, taking into account the above features.

\section{References}

1. E.G. Egorov, M.M. Nikiforov Bulletin of the North-Eastern Federal University named after M.K. Ammosov. Series: economics. Sociology. Culturology, 1(01), 7-16 (2016)

2. On the development of agriculture in the Republic of Sakha (Yakutia) Law of the Republic of Sakha (Yakutia) of 26.04.2016 1619-Z No. 791, Reference legal system ConsultantPlus

3. Agriculture in the Republic of Sakha (Yakutia): collected works (Sakha (Yakutia), Yakutsk, 2020)

4. E.G. Egorov, V.R. Darbasov, M.M, Nikiforov, S.G. Turantaev, Agrarian economy of the North. FSSE "Institute of regional economy of the North" (Yakutsk: Company "Dani Almas", 2008)

5. A.A. Pakhomov, E.Y. Fedorova, V.R. Darbasov, Food security of Yakutia: theory, practice (Novosibirsk, 2016)

6. N.N. Tikhonov, Severnoe Selo, Institute of Regional Economics (Novosibirsk: Nauka, 1996)

7. L.E. Ushnitskaya, Corporate governance and innovative development of the Northern economy: Bulletin of Scientific and Research Center of Corporate Law, Management and Venture Investment of Syktyvkar State University, 1, 212-219 (2013)

8. G.S. Vasilyeva, E.L. Vladimirova, S.A. Vladimirov et al., Society. Culture. (M.: Publishing House Academy of Natural Sciences, 2017)

9. N.N. Tikhonov, Yakutia - unique pantry of the planet (Novosibirsk: Nauka, 2013)

10. I.O. Poleshkina, Economics of the region, 3, 820-835 (2018) 